The Effects of Work Values on Job Choice Decisions

\author{
Timothy A. Judge \\ and \\ Robert D. Bretz, Jr. \\ Center for Advanced Human Resource Studies \\ School of Industrial and Labor Relations \\ Cornell University \\ Working Paper \# 91-23
}

This paper has not undergone formal review or approval of the faculty of the ILR School. It is intended to make results of Center research, conferences, and projects available to others interested in human resource management in preliminary form to encourage discussion and suggestions. 


\begin{abstract}
Work values have been receiving increased research attention. Ravlin, Meglino, and associates have recently conceptualized, and provided measurement of, work values. The effects of work values on job satisfaction, commitment, and individual decision making has been studied to date. However, work values have not been explicitly linked to job choice decisions. Using a sample of professional degree students and a policy capturing design, the influence of work values on job choice was examined in the context of job attributes that have previously been shown to affect this decision process. Work values were found to exhibit significant effects on job choice decisions. Further, individuals were more likely to choose jobs whose value content was similar to their own value orientation. Implications of the results for the study of work values and job choice are discussed.
\end{abstract}




\section{The Effects of Work Values on Job Choice Decisions}

Work values have been shown to be related to the way people feel about their work (Spence, 1985), the way people behave on their jobs (England, 1967, 1975) and their overall job satisfaction (Locke, 1976). More recently, Meglino, Ravlin, and Adkins (1989) reported increased job satisfaction and commitment when worker values were congruent with the values of their supervisors. Work values and their subsequent effect on work-related emotions, cognitions, or behaviors may result from selection of participants who possess particular value structures, socialization of organizational entrants, or a combination of both processes. Some research suggests that work values can be manipulated via socialization processes (Watson \& Barone, 1976; Watson \& Simpson, 1978). However, the more generally accepted view is that individuals establish relatively stable values through life experiences and that organizational socialization is unlikely to alter the basic value structure one brings to the organization (Lusk \& Oliver, 1974).

If values are relatively stable (Ravlin \& Meglino, 1989), it would be important to examine their role in the selection process since that would be the primary means through which person - organization value congruence may be achieved. Many organizations are now restructuring to achieve leaner and flatter organizational structures (Milkovich \& Boudreau, 1991). As a result of this restructuring, responsibility and decision making authority has been driven to lower levels in many organizations. Since an organization's culture and image are often closely tied to the value perspective an organization wishes to convey, it would seem that individual value orientation at all levels in the organization will become increasingly important in the future.

One conceptualization of values, consistent with many religious beliefs that people hold, is that values are enduring perspectives of what is fundamentally right or wrong 
(Rokeach, 1973). Alternatively, values can be thought of as preference or need for particular outcomes or states (England, 1967). Consistent with the latter perspective, Katz (1973) suggested that occupational choices could be viewed as preferences for settings that allow or encourage expression of particular values or value systems. Since job choice can be seen as an early step one takes to implement an occupational choice (Keon, Latack, \& Wanous, 1982), perhaps the occupational argument can be applied to jobs as well. Additionally, Vroom (1966) found that individuals made job choices consistent with their work goals. Some of these goals were value-laden (e.g., chance to benefit society, opportunity to advance), suggesting that individuals make job decisions based, in part, on their work values.

Early interactionist perspectives on motivational psychology viewed personenvironment fit in terms of matching individual needs and environmental press. Needs represent the determinants of behavior in individuals and can be inferred from (1) observed patterns of behavior, (2) attention, or particular responses, to specific stimuli, or (3) satisfaction or dissatisfaction with particular outcomes. Press represents the environmental determinants of behavior. Press implies what an object or environment can do for an individual to facilitate or hinder the fulfillment of internalized needs or the accomplishment of goals (Murray, 1938; Hall \& Lindzey, 1970). To the extent that values are internalized and affect motivation to fulfill certain needs, values may be expected to influence job choice decisions through need-press relationships. When faced with a choice, a person activated by particular value structures may be expected to seek out organizational environments that offer the opportunity for value expression and to avoid organizational settings that stifle or repress internalized values. Thus, decision making processes, of which job choice is one example, may be dependent on an individual's value system. 
Meglino et al.'s (1989) results indicated that individuals' perceptions of organizational fit also may be affected by their values. The authors suggested that their results underscored the importance of values in the organizational context. However, if satisfaction is derived from a match between individuals' values and those emphasized in the organization (Meglino et al., 1989), presumably individuals will make job choices in order to maximize their anticipated affect (Naylor, Pritchard, \& Ilgen, 1980). In other words, individuals may seek jobs where their values fit the organizational environment. Although there appears to be little agreement in the literature regarding the definition, application, or measurement of fit (Baird \& Meshoulam, 1988; Blau, 1987; Caldwell \& O'Reilly, 1990; Gresov, 1989; Rynes \& Gerhart, 1990; Venkatraman, 1989), Chatman (1989) has suggested that values are an appropriate means of conceptualizing fit, since individual and organizational values can be evaluated similarly. Thus, beyond the possible main effect of values on job choices, it is relevant to examine if the attractiveness of particular values in jobs depends on workers' own values.

Ravlin and Meglino (1987) examined the effect of work values on perception and decision making. Their results suggested that "values are hierarchically organized in memory, and ... that people will find opportunities, within the context of their duties, to apply their dominant value in uncertain situations" (p. 672). They further indicated that entry of individuals with particular dominant values might, in the long-term, influence the value orientation of the organization. This is consistent with Schneider's $(1983,1987)$ interactionist perspective. However, Ravlin and Meglino (1987) correctly pointed out that their results may be overstated since they were obtained in the absence of other contextual information. They called for additional research regarding the impact of values on individual processes, particularly their influence on choice behavior. This study attempts 
to provide that context by examining the impact of values in the job choice decision making process. Theoretically, it appears that values should have an impact on job choice decisions. One way to empirically test whether values actually are important is to empirically investigate their importance by examining their significance and relative effects in the context of variables (such as pay level and promotional opportunity) that have been shown to influence job choices.

A decade ago, Wanous (1980) lamented that although thousands of studies had been conducted regarding occupational choice decisions, very little was known about how job choices were made. Since then, we have substantially increased our understanding of the job choice process using a variety of methods and including a variety of variables. Direct attribute rating and policy capturing designs have been particularly instrumental in enhancing our understanding of job choice decision making. For example, Jurgensen's (1978) study of attribute importance found that individuals tended to report job security, type of work, advancement opportunity, and company characteristics as the most important attributes in their own job choice decisions but that pay was the most important attribute for others.

Priming artifacts created by supplying subjects with a predetermined list of "important" job attributes, and social desirability effects, such as the tendency to rate pay as less important than it really might be, represent deficiencies in direct estimation designs. Priming has not been an issue affecting values in job choice since they have not been included in researcher-supplied attribute lists. However, because of their highly desirable nature, social desirability effects may be particularly problematic in attribute rating job choice studies that include values. Work values are a subset of social values that suggest general patterns of behavior that individuals ought to exhibit (Fallding, 1965; Rokeach, 
1973). They are defined as valuable by society because it is important to society that individuals behave in certain ways and avoid behaving in other ways. Therefore, most members of society interpret social values as positive and endorse behaving in accordance with them. From a job choice perspective, this suggests that attempts to ascertain the relative importance of values vis-a-vis other determinants using direct estimation processes is undesirable.

Priming artifacts and social desirability effects led to the use of policy capturing designs in job choice research. With the introduction of values into the equation, this seems even more appropriate. Policy capturing designs (see Method section) have been used by many researchers to investigate the relative effects of a variety of independent variables on job preference and choice. For example, Feldman and Arnold (1978) reported that pay and benefits had greater influence on job choices than did opportunity to use important skills and abilities, autonomy and independence, responsibility, providing essential services and products, or flexibility in setting work schedules. Zedeck (1977) found that advancement opportunity emerged as the most important attribute, followed by salary, flexibility, and assignment duration. Rynes, Schwab, and Heneman (1983) examined the role of pay and market pay variability in job choice decisions. In their examination of salary, location, promotional opportunities, and type of work, they noted that pay was an important determinant of job attractiveness but concluded that greater pay variability increased the importance of pay in the decision making process.

Through these types of studies, our understanding of how job and organizational attributes, particularly pay and promotional opportunity, affect job choice decisions has been greatly enhanced. To date, however, our knowledge of how important values are in influencing job choice decisions remains limited because values have not been studied in 
the context of other variables that are known to influence job preference and choice.

It is important to study the effects of values on decision making using research designs that incorporate realistic levels of other contextual variables because people choose alternatives for a variety of reasons. While values may have an independent impact on decision making in some settings (Ravlin \& Meglino, 1987), Rynes et al. (1983) found evidence of non-compensatory processes in job choice decision making. Specifically, individuals identify certain necessary and sufficient conditions required for job acceptance. For instance, an individual may accept the first job that offers a particular salary level. Rynes et al. (1983) interpreted this to mean that non-pecuniary attributes may have an effect on job choice only when pecuniary attributes are within the relevant range. Therefore, research designs must accurately specify the pay level (and perhaps other important attributes) that subjects are likely to encounter in the actual job market and subsequent choice process in order to interpret the relative effects of other independent variables such as values.

Hypotheses

On the basis of pre-test results (see Method section) which generally confirmed past research (e.g. Schwab, 1982; Rynes et al., 1983), salary, promotion opportunities, and type of work were chosen as the most important job attributes to include in the study. Consistent with prior research, we expected salary and promotional opportunities to be positively related to an individual's preference for particular jobs. It was also expected that individuals who prefer generalist (specialist) work will be more likely to accept a generalist (specialist) position.

The values (achievement, helping others, honesty, and fairness) described by Ravlin and Meglino (1987) were used to study the effect of values on job choice decisions. As is 
explained later, work by Ravlin, Meglino, and others suggests that these four work values are the most prominent for individuals. Given the high level of social desirability of each of these values (England, 1975; Locke, 1976; Ravlin \& Meglino, 1987, 1989; Rokeach, 1973), it was hypothesized that the presence of these values would make the job appear more desirable. Therefore:

H1: A work environment where concern for others is emphasized will be positively related to individuals' decision to accept a given job offer.

H2: A work environment where achievement or hard work is emphasized will be positively related to individuals' decision to accept a given job offer.

H3: A work environment where honesty is emphasized will be positively related to individuals' decision to accept a given job offer.

H4: A work environment where fairness is emphasized will be positively related to individuals' decision to accept a given job offer.

Several individual differences other than values might also affect offer acceptance. While these relationships are not central to the purposes of this study, it was expected that certain individuals would be more likely to accept any job offer, perhaps mitigating the effects of individual value orientation. Particularly, it was expected that additional financial responsibilities such as those perceived by married job seekers would increase the likelihood of accepting any given job offer. It was also expected that perceived alternative employment opportunities would impact the decision making process. Specifically, individuals with lower grade point averages should be more likely to accept a given job offer. Alternatively, within a sample of student job seekers, older and more experienced individuals, perhaps having had experienced the dissatisfaction of accepting a job offer in haste, should be less likely to accept a given job offer. 
If values are an important determinant of person - organization fit (e.g. Chatman, 1989), individuals should make choices between jobs possessing different value characteristics based on their own individual values. Some research has demonstrated that individuals make job or vocational choices based on their personality characteristics (Holland, 1985; Martin \& Bartol, 1986; Monahan \& Muchinsky, 1985; Tom, 1971). This research has argued that individuals match their personality to the organization or vocation through the job or vocational choices they make. We expect the same matching process to occur with values. Specifically, we believe that the valence of a particular value in a job will depend on how important that value is to them. In other words, we hypothesize that value orientation of the individual will influence the attractiveness of value content in the job. Therefore:

H5: Individuals whose primary value orientation is fairness will be more likely than the other subjects to accept a job in an organization in which fairness is emphasized.

H6: Individuals whose primary value orientation is concern for others will be more likely than the other subjects to accept a job in an organization in which concern for others is emphasized.

H7: Individuals whose primary value orientation is honesty will be more likely than the other subjects to accept a job in an organization in which honesty is emphasized.

H8: Individuals whose primary value orientation is achievement or hard work will be more likely than the other subjects to accept a job in an organization in which achievement or hard work is emphasized. 


\section{Method}

Pre-Test

In order to identify the non-value factors most important in individuals' job choice decisions, students interviewing for jobs were surveyed and asked to rank (from 1 being most important to 5 being least important) five different characteristics of jobs that had been identified by past research (Rynes \& Lawler, 1983; Rynes et al., 1983; Schwab, Rynes, \& Aldag, 1987) as influential in job choice decisions. The five factors were salary level, advancement potential, geographic location, type of work, and type of organization. Twenty-eight students completed surveys. To control for social desirability bias (Jurgensen, 1978), individuals were asked to rank the importance of these factors according to how they thought others perceived them. The mean (M) and standard deviation (SD) of the ranks for the 5 factors were as follows: type of work $(\underline{M}=1.96, \underline{S D}=1.29)$; salary level $(\underline{M}=$ $2.50, \underline{\mathrm{SD}}=1.11) ;$ advancement potential $(\underline{\mathrm{M}}=2.86, \underline{\mathrm{SD}}=0.85) ;$ type of organization $(\underline{M}$ $=3.29, \underline{\mathrm{SD}}=1.54)$; and geographic location $(\underline{\mathrm{M}}=4.29, \underline{\mathrm{SD}}=1.01)$. The mean ranks for geographic location and type of organization were significantly lower than all other factors, except that the difference between advancement potential and type of organization failed to achieve significance.

\section{Setting. Subjects, and Procedure}

Surveys were administered to students enrolled in four professional degree classes at a university in the Northeastern U.S., and to students enrolled in several graduate classes at a large Midwestern university. Participation was voluntary, and confidentiality was assured in advance. In order to induce student participation, subjects completing surveys were eligible to win five lottery prizes of $\$ 25$. Eighty-seven students were eligible to participate. Sixty-seven students completed usable surveys, representing a response rate 
of $77 \%$. Of the 87 surveys distributed, 18 were given out to students at the Midwest university, and 14 were returned. The response rates between the two university samples were not significantly different.

Respondents' ages ranged from 20 to 49 years, with the average age equal to 26.2 years. Previous job experience ranged from no prior experience to 17 years experience, with an average of 3.1 years. Sixteen percent of respondents were married. Respondents from the Northeast university came from several degree programs, broadly consisting of graduate human resource majors (42\%), undergraduate human resource majors (21\%), and non human resource graduate students (including general management majors, 37\%). All students at the Midwest university were graduate human resource majors. Grade point average of respondents ranged from 2.7 to 4.0 , with an average of 3.51. Seventy-nine percent of the respondents were white, and $64 \%$ were women. Half of the respondents were currently interviewing for jobs, with the rest of the students expected to interview within a year. Sixty-nine percent of the respondents perceived acceptable employment opportunities while $32 \%$ perceived limited employment opportunities. Forty-five percent of respondents expressed a preference for a generalist human resource position, $32 \%$ preferred a specialist human resource position, and $23 \%$ expressed a preference for some other type of position such as general management.

Some differences were detected between the students at the Northeast and Midwest universities. Respondents at the Midwest university were significantly $(p<.01)$ younger and less experienced, more likely to be male, and had significantly higher grade-point averages than respondents at the Northeast university. On the other hand, no significant differences were detected on the following variables: marital status, type of work preferred, perceived employment alternatives, and beginning job search. Value orientation of the 
individuals also did not differ significantly between the groups. Furthermore, the mean offer acceptance was similar for both groups. Thus, while in most ways respondents at the two universities were similar, the diversity of the groups on some characteristics reinforces the advantage of collecting data from subjects at two sites.

Research Design and Measures

A mixed experimental design (Keppel, 1982), incorporating both within-subjects and between-subjects components, was used. The within-subjects design permits researchers to infer the relative importance of particular factors that are related to an individual's decision making. When the research question is focused on decision making, this design is known as policy capturing and has been used to study a variety of decision making processes within the organizational context, including disciplinary decisions (Klaas \& Wheeler, 1990), judgments of task importance (Sanchez \& Levine, 1989), managerial pay raise decisions (Sherer, Schwab, \& Heneman, 1987), judgments of sexual harassment (York, 1989), and, of course, job choice decisions (Arnold, 1981; Feldman \& Arnold, 1978; Rynes \& Lawler, 1983; Rynes et al., 1983; Zedeck, 1977).

In the present study, seven within-subjects factors (characteristics of job alternatives) were manipulated. The factors were pay, promotion opportunities, type of work (all identified from the pre-test), and the four value factors derived from Ravlin and Meglino's (1987) value classification. The levels of the pay and promotion figures were derived from data from the schools' career placement offices. Since average salary offers differed significantly between graduates and undergraduates, separate salary figures were provided in the graduate and undergraduate surveys. For graduate students at the Northeast university, an offer of $\$ 42,000$ represented the low offer (roughly the 25th percentile of offers accepted during the prior year); $\$ 46,000$ represented the high offer (roughly the 75 th 
percentile of offers accepted during the prior year). For the undergraduates at the Northeast university, these figures were $\$ 29,000$ and $\$ 33,000$, respectively. At the Midwest university, an offer of $\$ 38,000$ represented the low offer and $\$ 42,000$ represented the high offer (again roughly the 25th and 75th percentiles, respectively). Few promotion opportunities were indicated for all groups by having only 1 promotion in 5 years on the job. High promotion opportunities were indicated by 2 promotions in 5 years. These levels were determined through discussions with the schools' placement and alumni relations directors. Descriptions of the values were derived from Ravlin and Meglino's (1987) survey, which is explained later. Levels of the value factors were manipulated by indicating in the scenario either that the value was emphasized in the organization, or that it was not emphasized. It is important to note that the criterion was not whether the value was present or not but whether it was emphasized or not in the organization. This also was considered to facilitate a realistic treatment in the experiment and to be consistent with the ipsative nature of the values (cf. Ravlin \& Meglino, 1987).

The seven within-subjects independent variables were completely crossed which permits assessment of the independent effects of each factor on job choice decisions. Crossing the factors resulted in 128 scenarios $\left(2^{7}\right)$ which contained all possible combinations of the independent variables. The scenarios were presented in the survey in random order to minimize order effects. Each participant was asked to assume that they were offered a job possessing the characteristics included in the description. An example of a scenario is provided below, with the independent variables each description represents in parentheses.

The typical employee works very hard to fulfill work role obligations (achievement). The starting salary for this job is $\$ 46,000$ (pay). The emphasis is on helping others (concern for others). By the fifth year, the 
average graduate receives one promotion (promotion opportunities). It is best

to keep mistakes to yourself and do your best to correct the situation

(honesty). This is a specialist position in your area of interest (type of work).

Fairness is an important consideration in organizational activities (fairness).

The dependent variable, probability of accepting a job offer with the above characteristics, was measured by a question using a seven-point Likert scale. It was operationalized in the following manner: "Indicate the extent to which you would accept an offer possessing the above characteristics." The response scale was anchored by "highly unlikely' to 'highly likely.' Overall mean offer acceptance was 3.87 , close to the midpoint of the scale.

The between-subjects part of the design permits assessment of inter-individual differences based on individual attributes. Work values were assessed by the Comparative Emphasis Scale (CES), a survey developed and tested by Ravlin and Meglino (1987). Development of the CES was reported in DeNisi, Cornelius, and McNeely (undated), and is further reviewed in Ravlin and Meglino (1987), Meglino, Ravlin, and Adkins (1989), and Ravlin and Meglino (1989). The specific work values represented in the CES were chosen from a pool of many possible work values. Therefore, we can be confident that in general the work values assessed by the CES are the most salient and important to individuals. The CES presents 12 statements describing each of the four values. These 48 statements are divided into pairs such that a statement representing each of the four values is paired with each other value four times. For each pair, the individual is asked to check which value the respondent feels should be emphasized most in their own behavior. Each of the four comparison replications was randomized in order and in the value that appeared first in each pair. The emphasis on what the individual should or ought to display is consistent 
with most conceptualizations of social values (Rokeach, 1973). The result yields a purely ipsative measure of values (i.e., which values are most important to each individual relative to other values they consider). ${ }^{1}$

Primary value orientation was defined as the value preferred over the other values. For example, an individual who chose fairness over the other values 9 times, chose honesty over the other values 7 times, chose achievement over the other values 5 times, and chose concern for others over the other values 3 times, would be identified as having a fairness orientation. Five out the 67 subjects tied for most often selected value. For example, two individuals chose fairness and achievement an equal number of times (9) over the other values. These individuals were considered not to have a dominant value preference, and therefore were the excluded group. Primary value orientation was coded as 1 if the particular value was chosen more often than all others and 0 if it was not. Interactions between value orientation and value factors present in each job description were computed by multiplying the job factor by the relevant individual value orientation.

\section{Analyses}

Within-subjects analysis. Multiple regression analysis was used to assess the effects of the linear combination of the seven independent factors related to one's choice between job offers. Orthogonal contrast coding was used (Cohen \& Cohen, 1983). One regression equation was calculated for each participant.

Between-subjects analysis. Multiple regression was used to estimate the effect of the combination of job factors (within-subject variables), personal characteristics (betweensubject factors), and person and job value interactions on the probability of accepting an offer in an overall regression equation (collapsed across all subjects). Because individuals in different degree programs may face somewhat different labor markets, the degree 
program of the respondent might affect the perceived attractiveness of an offer. Therefore, the degree program of the respondent was controlled for in the analysis. Three dummy variables were formed from the four classifications of degree programs. For example, the Midwest university variable was coded 1 if the respondent was a student at the Midwest university and 0 otherwise. Undergraduates served as the excluded group in the analysis. Estimated time from present that the respondent intended to begin his or her job search (ranging from currently interviewing to interviewing in two years) was also used as a control to account for the possibility that the attractiveness of certain offers depended on whether the individual was currently interviewing, or depended on when they would begin interviewing.

\section{Results}

The correlation matrix of the between-subjects variables used in the analysis is reported in Table 1. Because the within-subjects manipulations were orthogonal, the correlations among the within-subjects factors and between the within- and between-subjects factors are zero. Therefore, they are not reported.

\section{Insert Table 1 About Here}

\section{Within-Subjects Analysis}

Within-subjects regression analysis was conducted for each participant. This yielded 67 equations. The results will be summarized here (a table which contains the 67 individual within-subjects regression equations can be obtained from the authors). There was wide variation in the extent to which the linear combination of within-subjects factors predicted offer acceptance decisions for each participant ( $\mathrm{R}^{2}$ ranged from .05 to .99 ). 
Average $\underline{\mathrm{R}}^{2}$ for the 67 participants was $.67(\underline{\mathrm{SD}}=.16)$.

Because each individual responded to 128 scenarios, it is possible that respondent fatigue affected the results. Such an effect might be detected by examining the variance explained in offer acceptance for the first 64 versus the last 64 scenarios. If the respondents, as they became fatigued, simply evaluated each scenario the same (i.e., used a response set), there would be no variation in the dependent variable, and the $\underline{R}^{2}$ would decrease. However, the difference in $\underline{R}^{2}$ between the first 64 and last 64 scenarios was only .009. Thus, individuals' responses to the scenarios did not appear to be affected by fatigue. The percentage of coefficients that were statistically significant $(p<.01)$ for each within-subjects factor was as follows: pay (57\%), promotion opportunities (58\%), type of work (28\%), achievement ( $81 \%)$, concern for others $(94 \%)$, honesty $(55 \%)$, and fairness (92\%). The absolute value of the coefficients' ranges were as follows: fairness (.02 to .86$)$; achievement (.01 to .70$)$; honesty (.01 to .58$)$; concern for others (.03 to .82 ); promotion opportunities (.00 to .69$)$; pay (.00 to .50$)$. For type of work, $46 \%$ of the significant coefficients were negative (specialist position) and 54\% were positive (generalist position).

In a few cases, some coefficients were negative. For example, with one subject the coefficient on concern for others was negative and significant (beta $=-.13$ ). With another subject, the coefficient on promotion opportunities was negative and significant (beta $=$ -.63). Coupled with the wide variance in the absolute value of factor coefficients (ranging from .00 to .82 ), this suggests that the attractiveness of job attributes varies considerably by individual. This underscores the importance of designs that enable one to evaluate withinsubject effects. For one individual, concern for others may be viewed as undesirable, perhaps being a sign of a Machiavellian orientation (Ferris \& Judge, 1991). For another, the availability of promotion opportunities may have been seen as undesirable because they 
may be seen as evidence of pressures to perform. For the purposes of this investigation, the particular reasons why a very few individuals may view certain job characteristics in an opposite manner to most may not be as important as the recognition that the valence of job attributes depends to a large extent on the individual. Purely between-subjects investigations are not capable of detecting these individual differences in preferences.

\section{Between-Subjects Analysis}

Table 2 provides the regression results for the probability of accepting an offer for the pooled sample. To be conservative given the large sample size, relatively low alpha levels (.01 and .001) were used for tests of statistical significance. Pay, promotion opportunities, and all four job value factors significantly influenced offer acceptance decisions. The effect of the value factors on job choices is generally stronger than the effect of pay and promotion. Thus, hypotheses 1 through 4 were supported by the results.

Insert Table 2 About Here

Concerning the between-subject influences, married individuals, those with low grade-point averages, younger and less experienced individuals, and those with few perceived alternative employment opportunities were more likely to accept a given job offer. As for the control variables, men were slightly more likely to accept a given job offer. Further, those who were either non-human resource or graduate human resource majors at the Northeast University were also somewhat more likely to accept a job offer. Finally, some of the value orientations exerted main effects on offer acceptance. Hypotheses were not made for individual value orientations because they were included in the equation to enable interpretation of the value orientation - job value factor interactions. 
Table 2 shows that the adjusted $\underline{\mathrm{R}}^{2}$ for the pooled sample was .39 . This is less than the average $\underline{R}^{2}$ for the individual equations (.67), which is to be expected since the pooled analysis collapses across unmeasured individual differences and differences in the valence of job attributes become part of the error term.

Interaction Analysis

Table 2 reveals that 4 of the 5 interactions were statistically significant. Analysis of variance yielded equivalent results. Inspection of the means revealed that all interactions were in the predicted direction. That is, mean offer acceptance was highest when there was a match between respondent value orientation and value present in the job. Thus, H5, H6, and $\mathrm{H} 8$ were supported by the results.

Table 3 provides a more detailed examination of the differing effects of job value characteristics on offer acceptances for the different value dominant groups. The results confirm the interactions reported in Table 2. Value factors present in a job best predict offer acceptance when the value emphasized matched the primary value orientation of the individuals. Table 3 demonstrates that both across individual value orientations (columnwise) and across the value content of jobs (row-wise), work values predicted job choices best when there was a match between individual and job values. This pattern held for all values except honesty.

Insert Table 3 About Here

Chow tests confirmed visual inspection of Table 3. Chow tests (Chow, 1960; Kennedy, 1985) allow one to determine if the effect of one or more independent variables differs between 2 or more groups. This is done by determining if pooling groups together 
(in this case pooling different value dominant groups) results in a significant increase in error sum of squares over separate estimation. In all cases other than honesty, pooling value orientations resulted in a significant increase in error sum of squares using the corresponding job value factor in predicting offer acceptance. Finally, the relations between the hypothesized influences on offer acceptance did not differ between the respondents of the Midwestern and Northeastern universities. This supports the generalizability of the results.

\section{Discussion}

The results presented in this paper suggest that individual value orientations have an important influence on job seekers' decisions when information about organizational value systems are known. The within-subject analyses found that concern for others, achievement orientation, and fairness all tended to exert more influence in the decision making process than did pay and promotional opportunities. The power of values relative to pay and promotional opportunities warrants comment. Pay and advancement potential have been shown to be important determinants of job attractiveness. In fact, in both direct inquiry and policy capturing studies of the job choice process these variables tend to emerge as very important attributes (e.g. Jurgensen, 1978; Feldman \& Arnold, 1978; Rynes et al., 1983; Zedeck, 1977). While these variables did achieve statistical significance in the current study, they emerged as somewhat less important than three of the four value orientations. Rynes et al. (1983) very clearly demonstrated that pay increases in importance as it becomes more variable. They also concluded that the effects of non-pecuniary attributes were interpretable only when pecuniary attributes were specified within the relevant range that subjects might expect in actual job choices. Special care was taken in the current study to insure that appropriate pay levels were used and that the variability of 
the pay levels was sufficient to indicate differences but not so great as to be unrealistic. The study could easily be replicated with greater variability in pay to both test the veracity of Rynes et al.'s (1983) arguments and to ascertain whether the limited effect of pay found in the current study is idiosyncratic to the sample. Of course, it also is true that since the within-subjects variables are orthogonal, the effect of findings concerning values in the sample are statistically unrelated to the effect of pay. Because it always is true with experimental designs that the effects observed depend on the realism of the experimental treatments, it also would be useful, although difficult, to replicate the results based on the characteristics of actual, versus hypothetical, job offers.

That values rather strongly influenced job choice decisions supports the efficacy of work values, as argued by Ravlin and Meglino $(1987,1989)$. Since values are often seen to be a central part of corporate culture (Meglino et al., 1989), the results of this study may provide indirect reinforcement to the importance of cultural factors to individuals choosing between organizations. This suggests that organizations may want to consider the messages they convey in the recruiting process. Since these values, as defined here, are almost universally viewed as highly desirable, organizations presenting an image of emphasizing these values may more successfully attract workers. Thus, while pay and mobility systems are important to individuals as they weigh job alternatives, value systems in organizations appear to be important as well.

The assessment of work values using the CES was also supported by the results. The hierarchical nature of values has driven considerable discussion regarding the work value construct and the appropriate manner in which to assess work values (England, 1975; Locke, 1976; Ravlin \& Meglino, 1987, 1989; Rokeach, 1973). Specifically, it is argued that although it may be difficult to preference order values because they tend to be highly 
socially desirable, it is exactly because they are highly socially desirable that preference ordering is requisite (Ravlin \& Meglino, 1987, 1989). Further, because the four values were significant predictors of offer acceptance, the efficacy of the specific values assessed by the CES was supported by the results. Therefore, we encourage future researchers interested in work value assessment to use preference ordering techniques such as the CES.

These results also support hypotheses that values are an important determinant of person - organization fit. Chatman (1989) and others have argued that many conceptualizations of fit are deficient because they have not considered contextual variables and organizational value systems that are likely to exert strong influence over individuals' behavior. Additionally, Chatman (1989) has argued convincingly that person - organization fit is best determined by scales that can be used to measure both individual and organizational characteristics. The current study attempts to address the measurement issue by assessing individual values with the scale suggested by Ravlin and Meglino (1987) and indicating organizational value orientations with summary statements of the values expressed in that scale. Additionally, the values are presented within the context of each other and other important variables such as type of work, salary, and promotional opportunity.

For all values except honesty, the values present in a job best predict offer acceptance when the value emphasized matched the primary value orientation of the individual. It is not clear from the results why the value interaction did not hold for honesty. One explanation may be that the way honesty was manipulated, although consistent with Ravlin and Meglino (1987), was not valid. Since conclusions about experimental treatments depend on the validity of the manipulations, caution is probably warranted in interpreting the results concerning honesty. Another possible explanation 
concerning the weakness of the honesty interaction might be the weakness of the honesty factor relative to the other value factors in predicting job choice decisions. If the degree to which honesty is emphasized makes a relatively minor difference to individuals in their choice of jobs, then it may be less important, in this case, that the value orientation matches the value present in the job. In other words, the influence of fit on job choice may depend on the importance of the factor to the individual. It was also true that across value groups, the job values had the greatest effect when consistent with the primary value orientation of the individual (true for all values except fairness).

Given the results of this study suggesting that value congruence predicts job choice, more work is clearly called for in this area. For example, while job matching based on value congruence may operate when values present in the job are salient, our study is not informative with respect to how often information about organizational value orientations is available to job seekers, or how often values present in the job or organization actually are salient to the individual. Work values can only influence decisions when they are perceived. Further research needs to address the extent to which value salience exists in job choice situations and what implications this has for job choices individuals make.

Future research should also consider how people get information about organizational values, which sources provide which type of information and what assumptions job applicants make about organizational values based on knowledge of observable organizational characteristics. For example, it is possible that job seekers' perceptions of organizational values may be influenced by the organization's environmental protection policy or by how it reacts to environmental disasters (e.g., the Exxon Valdez incident). Since the results of this study suggest that value information has significant influence on applicant's job choice decisions, how that information is acquired seems to be 
an important research question.

Further, the person - organization fit literature suggests that individuals who match job or organization values to their own will be more satisfied and less likely to leave the organization. It would be useful for future research to follow job choices through to issues of perceived fit, and the consequences of value congruence and perceived fit on individuals once in the organization.

While this study contributes to our understanding of the role of values in both the job choice process and in person - organization fit, replication of the results using different populations is necessary, particularly those with different education levels and opportunity wages. The similar results observed in the two university samples, despite some important differences between the groups, suggests that the results may generalize to several types of workers and job seekers. Nevertheless, we are more confident that the results generalize to graduate and undergraduate job seekers (an increasing segment of the work force) than to those less educated. Future studies of values in job choice and person - organization fit that include samples drawn from diverse populations would build on these results and answer generalizability questions that may exist. 


\section{References}

Arnold, H.J. (1981). A test of the validity of the multiplicative hypothesis of expectancyvalence theories of work motivation. Academy of Management Journal, 24, 128141.

Baird, L., \& Meshoulam, I. (1988). Managing two fits of strategic human resource management. Academy of Management Review, 13, 116-128.

Blau, G.L. (1987). Using a person-environment fit model to predict job involvement and organizational commitment. Journal of Vocational Behavior, $\underline{30,}$ 240-257.

Caldwell, D.F., \& O'Reilly, C.A. (1990). Measuring person-job fit with a profilecomparison process. Journal of Applied Psychology, 75, 648-657.

Chatman, J.A. (1989). Improving interactional organizational research: A model of person-organization fit. Academy of Management Review, 14, 333-349.

Chow, G.C. (1960). Tests of equality between sets of coefficients in two linear regressions. Econometrica, 28, 591-605.

Cohen, J., \& Cohen, P. (1983). Applied multiple regression/correlation analysis for the behavioral sciences. Hillsdale, NJ: Erlbaum.

DeNisi, A.S., Cornelius, E.T., \& McNeely, B. (undated). A preliminary test of an indirect approach to study worker values: Identification of values and demographic differences. Unpublished manuscript.

England, G.W. (1967). Organizational goals and expected behavior of American managers. Academy of Management Journal, 10, 107-117.

England, G.W. (1975). The manager and his values: An international perspective from the United States, Japan, Korea, India, and Australia. Cambridge, MA: Ballinger. 
Fallding, H. (1965). A proposal for the empirical study of values. American Sociological Review, $\underline{30}, 223-233$.

Feldman, D.C., \& Arnold, H.J. (1978). Position choice: Comparing the importance of organizational and job factors. Journal of Applied Psychology, 63, 706-710.

Ferris, G.R., \& Judge, T.A. (1991). Personnel/human resource management: A political influence perspective. Journal of Management, 17, 1-42.

Gresov, C. (1989). Exploring fit and misfit with multiple contingencies. Administrative Science Quarterly, 34, 431-453.

Hall, C.S., \& Lindzey, G. (1970). Theories of personality (2nd ed.). New York: John Wiley \& Sons, Inc.

Holland, J.L. (1985). Making vocational choices: A theory of vocational personalities \& work environments (2nd ed.). Englewood Cliffs, NJ: Prentice-Hall.

Jurgensen, C.E. (1978). Job preferences (What makes a job good or bad?). Journal of Applied Psychology, 50, 479-487.

Katz, M. (1973). The name and nature of vocational guidance. In H. Borrow (Ed.), Career guidance for a new age. Boston: Houghton Mifflin.

Keon, T.L., Latack, J.C., \& Wanous, J.P. (1982). Image congruence and the treatment of difference scores in organizational choice research. Human Relations, 35, 155-166.

Kennedy, P. (1985). A guide to econometrics. Cambridge, MA: MIT Press.

Keppel, G. (1982). Design and analysis: A researcher's handbook (2nd ed.). Englewood Cliffs, NJ: Prentice-Hall.

Klaas, B.S., \& Wheeler, H.N. (1990). Managerial decision making about employee discipline: A policy-capturing study. Personnel Psychology, 43, 117-133. 
Work Values and Job Choice 28

Locke, E.A. (1976). The nature and consequences of job satisfaction. In M.D. Dunnette (Ed.), Handbook of industrial and organizational psychology (pp. 1297-1349). Chicago: Rand-McNally.

Lusk, E., \& Oliver, B. (1974). American managers' personal value systems revisited. Academy of Management Journal, 17, 549-554.

Martin, D.C., \& Bartol, K.M. (1986). Holland's Vocational Preference Inventory and the Myers-Briggs Type Indicator as predictors of vocational choice among master's of business administration. Journal of Vocational Behavior, 29, 5165.

Meglino, B.M., Ravlin, E.C., \& Adkins, C.L. (1989). A work values approach to corporate culture: A field test of the value congruence process and its relationship to individual outcomes. Journal of Applied Psychology, 74, 424-432.

Milkovich, G.T., \& Boudreau, J.W. (1991). Human resource management (6th ed.). Homewood, IL: Irwin.

Monahan, C.J., \& Muchinsky, P.M. (1985). Intrasubject predictions of vocational preference: Convergent validation via the decision theoretic paradigm. Journal of Vocational Behavior, 27, 1-18.

Murray, H.A. (1938). Explorations in personality. New York: Oxford University Press. Naylor, J.C., Pritchard, R.D., \& Ilgen, D.R. (1980). A theory of behavior in organizations. New York: Academic Press.

Ravlin, E.C., \& Meglino, B.M. (1987). Effects of values on perception and decision making: A study of alternative work values measures. Journal of Applied Psychology, 72, 666-673. 
Ravlin, E.C., \& Meglino, B.M. (1989). The transitivity of work values: Hierarchical preference ordering of socially desirable stimuli. Organizational Behavior and Human Decision Processes, 44, 494-508.

Rokeach, M. (1973). The nature of human values. New York: Free Press.

Rynes, S.L., \& Gerhart, B. (1990). Interviewer assessments of applicant "fit": An exploratory investigation. Personnel Psychology, 43, 13-35.

Rynes, S.L., \& Lawler, J. (1983). A policy-capturing investigation of the role of expectancies in decisions to pursue job alternatives. Journal of Applied Psychology, 68, 620-631.

Rynes, S.L., Schwab, D.P., \& Heneman, H.G. (1983). The role of pay and market pay variability in job application decisions. Organizational Behavior and Human Performance, 31, 353-364.

Sanchez, J.I., \& Levine, E.L. (1989). Determining important tasks within jobs: A policy-capturing approach. Journal of Applied Psychology, 74, 336-342.

Schneider, B. (1983). An interactionist perspective on organizational effectiveness. In K.S. Cameron \& D.A. Whetten (Eds.), Organizational effectiveness: A comparison of multiple models (pp. 27-54). Orlando, FL: Academic Press.

Schneider, B. (1987). The people make the place. Personnel Psychology, 40, 437-453.

Schwab, D.P. (1982). Recruiting and organizational participation. In K.M. Rowland \& G.R. Ferris (Eds.), Personnel management (pp. 103-127). Boston: Allyn and Bacon. Schwab, D.P., Rynes, S.L., \& Aldag, R.J. (1987). Theories and research on job search and choice. In K.M. Rowland and G.R. Ferris (Eds.), Research in personnel and human resource management (pp. 129-166). Greenwich, CT: JAI Press. 
Sherer, P.D., Schwab, D.P., \& Heneman, H.G. (1987). Managerial salary-raise decisions: A policy-capturing approach. Personnel Psychology, 40, 27-38.

Spence, J.T. (1985). Achievement American style: The rewards and costs of individualism. American Psychologist, 40, 1285-1295.

Tom, V.R. (1971). The role of personality and organizational image in the recruiting process. Organizational Behavior and Human Performance, $\underline{6}$, 573-592.

Venkatraman, N. (1989). The concept of fit in strategy research: Toward verbal and statistical correspondence. Academy of Management Review, 14, 423-444.

Vroom, V.H. (1966). Organizational choice: A study of pre- and postdecision processes. Organizational Behavior and Human Performance, 1, 212-225.

Wanous, J. (1980). Organizational entry: Recruitment, selection, and socialization of newcomers. Reading, MA: Jossey-Bass.

Watson, J.G., \& Barone, S. (1976). The self-concept, personal values, and motivations orientations of black and white managers. Academy of Management Journal, 19, 3648.

Watson, J.G., \& Simpson, L.R. (1978). A comparative study of owner-manager personal values in black and white small business. Academy of Management Journal, 21, 319325.

York, K.M. (1989). Defining sexual harassment in workplaces: A policy-capturing approach. Academy of Management Journal, $\underline{32}$, 830-850.

Zedeck, S. (1977). An information processing model and approach to the study of motivation. Organizational Behavior and Human Performance, 18, 47-77. 


\section{Author Notes}

The authors thank Shinichiro Watanabe for assistance with data entry and Jack Howard for assistance with data collection. The authors also thank Ed Locke and Sara Rynes for helpful comments on an earlier version of this manuscript. Correspondence regarding this article may be addressed to Tim Judge or Bob Bretz, Center for Advanced Human Resource Studies, 393 Ives Hall, Ithaca, New York 14853-3901. 


\section{Footnote}

1. Rather than classify subjects ipsatively according to value preference, it was thought useful to be able to classify them on a rating scale, facilitating comparisons between subjects. However, the value subscales possessed very poor discriminant validity from one another. Reliabilities composed of random ordering of the values yielded equally high reliabilities (alphas between .93 and .99) as those classified by each of the four values. Further, the scales correlated very highly with each other (the average correlation between the value scales was .98). This may be due in part to the socially desirable nature of these values (Ravlin \& Meglino, 1987). Ravlin and Meglino (1987) suggested that despite the fact that Likert-type scales are more amenable to between-subject comparisons, ipsative scales appear to yield a more accurate and useful classification of value preferences. Our results appear to confirm this. Therefore, the ipsative scale was used. 
Table 1

Correlations of Between-Subject Variables

\begin{tabular}{|c|c|c|c|c|c|c|c|c|c|c|c|c|c|c|c|c|c|c|c|c|c|c|}
\hline & & 1 & 2 & 3 & 4 & 5 & 6 & 7 & 8 & 9 & 10 & 11 & 12 & 13 & 14 & 15 & 16 & 17 & 18 & 19 & 20 & 21 \\
\hline 1 & Married & - & 09 & -13 & 24 & 03 & 13 & 02 & -10 & -13 & 04 & -09 & 01 & -07 & -09 & 03 & -05 & 32 & 38 & 35 & 34 & 01 \\
\hline 2 & Male & & - - & 31 & -08 & 01 & 30 & 09 & -16 & -08 & 21 & -14 & 05 & -11 & -05 & 14 & -08 & -10 & -05 & 08 & -15 & 07 \\
\hline 3 & Midwest Univ. & & & -- & -34 & -36 & 30 & 05 & -11 & -08 & 09 & -05 & 03 & -08 & -06 & 06 & -03 & -23 & -29 & -10 & -01 & 04 \\
\hline 4 & Non HR Major & & & & - & -46 & 00 & 04 & -14 & 07 & 00 & 06 & 02 & -10 & 04 & 00 & 03 & 43 & 39 & 06 & 38 & -03 \\
\hline 5 & Grad HR Major & & & & & - - & 12 & 16 & 16 & -12 & -11 & -14 & 09 & 11 & -08 & -08 & -08 & 01 & -00 & 10 & -34 & 02 \\
\hline 6 & GPA & & & & & & - & -07 & -11 & -01 & 11 & -07 & -04 & -08 & -00 & 07 & -04 & 02 & -09 & 07 & 03 & 07 \\
\hline 7 & V-Fairness & & & & & & & - - & -23 & -54 & -44 & -32 & 57 & -16 & -36 & -30 & -18 & 11 & 03 & 04 & -12 & 02 \\
\hline 8 & V-Help & & & & & & & & -- & -11 & -09 & -10 & -13 & 70 & -07 & -06 & -05 & -13 & -14 & -19 & -06 & 00 \\
\hline 9 & V-Achieve & & & & & & & & & - - & -22 & 32 & -31 & -08 & 66 & -15 & 18 & -03 & 15 & -02 & 01 & 04 \\
\hline 10 & V-Honest & & & & & & & & & & -. & 04 & -25 & -06 & -14 & 68 & 02 & .07 & -11 & 04 & 08 & -05 \\
\hline 11 & V-Generalist & & & & & & & & & & & - & -18 & -07 & 21 & 03 & 56 & 06 & 11 & -11 & 09 & 02 \\
\hline 12 & Fairness-Int & & & & & & & & & & & & - & -09 & -20 & -17 & -10 & 07 & 02 & 02 & -07 & 28 \\
\hline 13 & Help-Int & & & & & & & & & & & & & - - & -05 & -04 & -04 & -09 & -10 & -13 & -04 & 09 \\
\hline 14 & Achieve-Int & & & & & & & & & & & & & & - & -10 & 12 & -02 & 10 & -01 & 00 & 14 \\
\hline 15 & Honest-Int & & & & & & & & & & & & & & & $\cdots$ & 02 & -05 & -07 & 02 & 05 & 00 \\
\hline 16 & Work-Int & & & & & & & & & & & & & & & & - & 03 & 06 & -06 & 05 & 06 \\
\hline 17 & Age & & & & & & & & & & & & & & & & & - - & 79 & 02 & 47 & -15 \\
\hline 18 & Experience & & & & & & & & & & & & & & & & & & -- & 17 & 37 & -16 \\
\hline 19 & Alternatives & & & & & & & & & & & & & & & & & & & - & 03 & -08 \\
\hline 20 & Begin Search & & & & & & & & & & & & & & & & & & & & -- & -06 \\
\hline 21 & offer & & & & & & & & & & & & & & & & & & & & & -- \\
\hline
\end{tabular}

Note: Decimals are omitted. Correlations greater than .03 are significant at the .011 level. Variables 7-11 indicate primary value orientation of individual. Variables 12-16 indicate interactions between primary value orientation of individual and emphasis of that value in job. With variables 3-5, undergraduate is excluded group. With variables 7-10, individuals with ties between value preferences represent the excluded group. 
Table 2

Overall Regression Equation Predicting Job Choice Decisions

$\begin{array}{ccc}\text { Independent Variable } & \text { Betandard } \\ \text { Error }\end{array}$

\title{
Within-subjects Factors
}

\author{
Pay \\ Promotion Opportunities \\ Generalist Position \\ Concern for Others \\ Achievement \\ Honesty \\ Fairness
}

$\begin{array}{rr}.11^{x x} & .03 \\ .12^{x x} & .03 \\ -.03^{x} & .04 \\ .27^{x x} & .03 \\ .17^{x x} & .03 \\ .10^{x x} & .03 \\ .32^{x x} & .04\end{array}$

Between-8ubjects Factors

\begin{tabular}{|c|c|c|}
\hline $\begin{array}{l}\text { Married } \\
\text { Male } \\
\text { Midwest University } \\
\text { Non Human Resource Major } \\
\text { Graduate Human Resource Major } \\
\text { Grade-Point Average } \\
\text { Age } \\
\text { Experience } \\
\text { Perceived Alternatives } \\
\text { Begin Job Search } \\
\text { Value Fairness } \\
\text { Value Helping Others } \\
\text { Value Hard Work } \\
\text { Value Honesty } \\
\text { Value Generalist Work }\end{array}$ & $\begin{array}{r}.13^{x x} \\
.06^{x x} \\
-.01 \\
.05^{x x} \\
.05^{x} \\
.04^{x} \\
-.09^{x x} \\
-.18^{\times x} \\
-.10^{x x} \\
.02 \\
.06^{x} \\
-.04^{x} \\
.07^{x x} \\
-.02 \\
.00\end{array}$ & $\begin{array}{l}.05 \\
.04 \\
.06 \\
.06 \\
.06 \\
.01 \\
.01 \\
.01 \\
.02 \\
.01 \\
.07 \\
.12 \\
.08 \\
.08 \\
.04\end{array}$ \\
\hline \multicolumn{3}{|l|}{ it Interactions } \\
\hline $\begin{array}{l}\text { Value Fairness } x \text { Fairness } \\
\text { Value Helping Others } x \text { Concern for others } \\
\text { Value Hard Work } x \text { Achievement } \\
\text { Value Honesty } x \text { Honesty } \\
\text { Value Generalist Work } x \text { Generalist Position }\end{array}$ & $\begin{array}{l}.11^{x \times} \\
.09^{x x} \\
.09^{x x} \\
.02 \\
.10^{x x}\end{array}$ & $\begin{array}{l}.06 \\
.14 \\
.07 \\
.08 \\
.06\end{array}$ \\
\hline usted $\mathrm{R}^{2}$ & & \\
\hline
\end{tabular}

$x_{\underline{p}}<.01{ }^{x} \underline{p}<.001 \quad \underline{N}=8,562$ 
Table 3

Within-Subject Job Choice Regressions by Value Preference

\begin{tabular}{|c|c|c|c|c|}
\hline \multirow[b]{2}{*}{ within-Subject Factor } & \multicolumn{4}{|c|}{ Individual value Preference } \\
\hline & A & C & $\mathbf{F}$ & $\mathbf{H}$ \\
\hline Generalist Position & $\begin{array}{l}.09 \\
(.07)\end{array}$ & $\begin{array}{l}-.05 \\
(.12)\end{array}$ & $\begin{array}{l}.01 \\
(.04)\end{array}$ & $\left(.16^{x x}\right.$ \\
\hline Pay & $\begin{array}{l}.10^{x x} \\
(.07)\end{array}$ & $\begin{array}{l}.05 \\
(.12)\end{array}$ & $\left(.12^{x x}\right.$ & $\begin{array}{l}.09^{x x} \\
(.08)\end{array}$ \\
\hline Promotion Opportunities & $\begin{array}{l}.09^{x x} \\
(.07)\end{array}$ & $\begin{array}{l}.08^{x} \\
(.12)\end{array}$ & $\begin{array}{l}.13^{x x} \\
(.04)\end{array}$ & $\left(.13^{x x}\right.$ \\
\hline Concern for others & $\begin{array}{l}.19^{x x} \\
(.07)\end{array}$ & $\begin{array}{l}.54^{x x} \\
(.12)\end{array}$ & $\begin{array}{l}.33^{x x} \\
(.04)\end{array}$ & $\begin{array}{l}.18^{x x} \\
(.08)\end{array}$ \\
\hline Fairness & $\begin{array}{l}.27^{x x} \\
(.07)\end{array}$ & $\begin{array}{l}.49^{x x} \\
(.12)\end{array}$ & $\begin{array}{l}.44^{x x} \\
(.04)\end{array}$ & $\begin{array}{l}.29^{x x} \\
(.08)\end{array}$ \\
\hline Honesty & $\begin{array}{l}.04^{x} \\
(.07)\end{array}$ & $\left(.12^{x x}\right.$ & $\left(.041^{x x}\right.$ & $\begin{array}{l}.14^{x x} \\
(.08)\end{array}$ \\
\hline Achievement & $\begin{array}{l}.32^{x x} \\
(.07)\end{array}$ & $\begin{array}{l}.14^{x x} \\
(.12)\end{array}$ & $\begin{array}{l}.19^{x x} \\
(.04)\end{array}$ & $\begin{array}{l}.16^{x x} \\
(.08)\end{array}$ \\
\hline $\mathbf{R}$ & $.48^{x x}$ & $.76^{x x}$ & $.62^{x x}$ & $.46^{x x}$ \\
\hline Adjusted $\mathrm{R}^{2}$ & .23 & .58 & .38 & .21 \\
\hline (Number of Individuals) & $\begin{array}{r}1,792 \\
(14)\end{array}$ & $\begin{array}{l}384 \\
(3)\end{array}$ & $\begin{array}{l}4,480 \\
(35)\end{array}$ & $\begin{array}{r}1,280 \\
(10)\end{array}$ \\
\hline
\end{tabular}

$x_{p}<.011^{x} \underline{p}<.001$

Note: Estimates are standardized regression coefficients. standard errors are in parentheses.

$A=$ Achievement/hard work most important $C=$ Concern for others most important $F=$ Fairness in dealing with others most important $\mathrm{H}=$ Honesty most important 